\title{
Rethinking gesture theory via embodiment and acousmatic music
}

\author{
Hubert $\mathrm{Ho}^{1 \dagger}$ \\ ${ }^{1}$ Northeastern University, Boston, MA, USA \\ $\dagger$ Corresponding author: h.ho@northeastern.edu
}

Published 16 December 2021; https://doi.org/10.18061/FDMC.2021.0034

Author video presentation and/or other conference material: https://doi.org/10.17605/OSF.IO/G3YRP

\begin{abstract}
The crucial role of embodiment in perceiving music is increasingly well documented by cognitive scientists and music theorists. Less thoroughly explored is the role that embodied cognition plays in our hearing of acousmatic music. Primarily produced on digital audio workstations, and diffused through loudspeakers, this genre of music has often been critiqued because the sources producing the sound do not neatly map onto specific sound-producing actions.

This paper proposes an analytical model utilizing gesture theory (Leman and Godøy, 2010) in framing an embodied listening approach to acousmatic music. Gesture, defined as a "pattern through which we structure our environment through actions," (Leman and Godøy, 2010), allows listeners to assign specific musical meaning to the disembodied sounds. The model focuses specifically on sound-tracing gestures that "follow the contour of sonic elements" (Godøy et al., 2006) of the acousmatic track. A multidimensional analytic approach focused on three parameters crucial to contour understanding (localization, causality, mobility) (Frengel, 2010) in acousmatic music is applied to Jonathan Harvey's Mortuos Plango, Vivos Voco. This work thus broadens the scope of an embodied approach to music cognition as it applies to music analysis.
\end{abstract}

KEYWORDS: embodied cognition, gesture, embodiment, electroacoustic music, acousmatic music

\section{Literature Review}

Researchers have noted how embodied cognition plays an increasingly important role in music perception. Perceiving music activates the action-perception network (Maes et al., 2014) in listeners. Expert pianists demonstrate greater levels of connectivity in brain regions linked to the mirror neuron system (Gallese et al., 1996) while observing other pianists (Haslinger et al., 2005). Other studies demonstrate listening subjects' ability to match body movement to specific acoustical traits (Eitan and Granot, 2006). Leveraging this evidence, music theorist Arnie Cox (2016) proposes that mimetic motor imagery (MMI) and mimetic motor action (MMA) underlie musical experience and has developed a number of frameworks for situating the action-perception network at the core of musical analytical activity.

The research on musical gesture from a variety of perspectives (music cognition, embodiment, music theory, computer music) is increasingly varied. Leman and Godøy (2010) define a musical gesture as a "pattern through which we structure our environment through action." Jensenius et al. (2010) outlines four categories of gesture; the categories "point out ... the different functions of gestures" rather than substantiate any "absolute" classification scheme: 1) Sound-producing (sub-divided into actions that excite the sound, and actions that modify sound), 2) Sound-facilitating, 3) Sound-accompanying and 4) Communicative. Gestures might function in more than one way; and gestures can overlap, blending from one to another.

Gestural conceptualization of music operates from the perspective of both the musical agent (composer, performer) and listener. Cox (2016) proposes that listeners enact a surreptitious simultaneous performance while listening to music, a phenomenon he calls "subvocal mimetic participation." This process creates "mimetic musical imagery" in listeners' mental representations as if the listener imagined what the process of performance might be. Thus, according to Cox, musical meaning is derived from the ability to link musical phenomena to action-based correlates.

Prior research in computer music has wrestled with the distinction between a gesture that a musician or composer enacts, and that of a programmer. For Cadoz (1998), "[i]n the case of musical writing, the subject intervenes to decode the signs and interpret them in function of established conventions ... the instrumental gesture is a direct causal component of the sound phenomenon."

Electroacoustic (EA) music presents an ontological problem from the perspective of the action-perception cycle, as the agents who produced the sounds in the first place (developer of synthesis programs, or artists who recorded sound samples) are not visible to the listener in 
the performance space. EA work is typically diffused through loudspeakers in indoor concert spaces in concert settings. Furthermore, spatialization and resonance are central to much EA and sound art aesthetics; composers and sound assistants consider the acoustics of performance spaces and loudspeaker placement when diffusing works of musique concrète.

\section{Method}

This initial study focuses on expanding and revising the gesture model of Leman and Godøy (2010) and Godøy et al. (2006) to account for situations highly salient to acousmatic (without live performers) music. Godøy et al. (2006) asks participants to draw out tracings of sonic gestures. This short paper will also center on issues of movement and tracing, drawing upon a multidimensional approach utilized to codify relationships between instruments and fixed media tracks (Frengel, 2010). It will also address issues of causality (sound sourcing) and propose embodied analogues for all three processes. Jonathan Harvey's Mortuos Plango, Vivos Voco will be referenced as an exemplification these processes.[1]

\section{Localization}

A CONTAINER [2] is a useful metaphor to describe how a listener might locate themselves in a musical work ("We hear the first theme in the exposition," "We are in the key of E minor."). Acousmatic musical audience members are physically situated in a space, putting themselves - as sentient, perceiving, and listening beings - inside of the space through which sound propagates. Listeners identify the sound sources and become attuned to their directionalities according to classical psychophysical principles determined by interaural time difference and interaural intensity difference. Harvey plays with localization techniques compositionally, noting that "[r]hythmic patterns of great subtlety were easy to devise, sometimes in interplay with programmed spatial movement" (Harvey, 1980) during a performance at IRCAM. Harvey also "individually distributed [partials of the bell] around the eight speakers, giving the listener the curious sensation of being inside the bell." That spatialization plays such a significant role within the confines of the performance space, does not negate the piece's ability to induce more metaphorical assertions of musical place in the piece. In fact, the co-existence of both modes of localization, the literal and the metaphoric, is grounds for further discussion.

\section{Mobility}

Auditory images can consist of sounds travelling within a concert or listening space, either as a result of a specific prerecorded mixing techniques or live diffusion techniques ("The bell sound moves from left to right."). But once again, as music itself is considered to both induce movement and represent motion ("The intervals are getting closer and closer"), the musical journey operates on both literal and metaphoric levels. This duality is demonstrated at 2:45, when the resynthesized spectra from vowels of a boy's voice move in contrary motion inwards as glissandi (Harvey, 24).

\section{Causality}

While loudspeakers serve as the units of sonic production in EA concert settings, audiences tend not to comment on their agency (or lack thereof) as musical units. They are more likely to focus on the indirect sources of the sound, either samples or synthesized materials. According to Frengel (2010), "Strong timbral associations are likely to occur whenever the non-live sounds are based on recordings." This enhances source identification of the sound, rendering the Schaefferian prescription for a "reduced listening" (that ignores such recognition) sometimes difficult. The opening of Harvey's work (0:00-0:24) presents both source sounds in highly recognizable fashion - a boy's voice that emerges from a group of bells sampled from the Winchester Cathedral, England - but eventually gives way to manipulations that render the sources unrecognizable (see example above from 2:45). Listeners, according to Cox, participate subvocal[ly] mimetic[ally], regardless of whether the sounds they hear remain untransformed or digitally processed.

At 6:34-6:54, Harvey reverts to the recognizable bell timbre and treats it as an isochronous repeating rhythmic percussive unit, supporting chorusing effects. Interestingly, this section resembles instrumental writing, as the timing of the onsets and the instrumental nature of the bell sound might be perceived as an ensemble.

\section{Conclusion}

This paper provides the basis of a revised model of embodied cognitive approaches to the analysis of acousmatic music, taking into account the compositional techniques, aesthetics, and listening practices of sonic localization, mobility, and causality. It focuses on how models of musical gesture can be refined to take into account more literal presentations of 
what is often conceived of as metaphoric. Further research will consider other dimensionalities of acousmatic music - reverberation, accretion/addition, looming-sense, timbre (beyond source recognition), sonic morphologies - and incorporate them into the model.

\section{End Notes}

[1] A detailed analysis of the piece is given in Dirks (2007)

[2] Here the convention of labelling metaphor types using small caps follows that set out by Lakoff and Johnson (1980).

\section{References}

Cadoz, C. (1988). Instrumental Composition and Musical Gesture. In Proceedings of the 1988 International Computer Music Conference. The Hague, The Netherlands, 60-73.

Cox, A. (2016). Music and Embodied Cognition. Oxford: Oxford UP. https://doi.org/10.2307/j.ctt200610s

Dirks, P. L. (2007). An Analysis of Jonathan Harvey's "Mortuos Plango, Vivos Voco." eContact! 9(2). https://econtact.ca/9_2/dirks.html

Eitan, Z., and Granot, R. Y. (2006). How music moves: musical parameters and listeners images of motion. Music Percept. 23, 221-248. https://doi.org/10.1525/mp.2006.23.3.221

Frengel, M. (2010). A Multidimensional Approach to Relationships between Live and Non-live Sound Sources in Mixed Works. Organised Sound 15(2), 96-106. https://doi.org/10.1017/S1355771810000087

Gallese, V., Fadiga, L., Fogassi, L., \& Rizzolatti, G. (1996). Action recognition in the premotor cortex. Brain 119, 593-609. https://doi.org/10.1093/brain/119.2.593

Godøy, R. Haga, E. \& Jensenius, A. (2006). Exploring music-related gestures by sound-tracing: a preliminary study. In K. Ng (Ed.), Proceedings of the COST287ConGAS $2^{\text {nd }}$ International Symposium on Gesture Interfaces for Multimedia Systems. Leeds, UK, 27-33.

Harvey, J. (1980). Mortuos Plango, Vivos Voco. On Mortuos Piango, Vivos Voco: The Essential Works Of Jonathan Harvey [MP3 file]. London, UK: Sargasso. (2013)

Harvey, J. (1981). "Mortuos Plango, Vivos Voco": A Realization at IRCAM. Computer Music Journal 5(4), 22-24. https://doi.org/10.2307/3679502

Haslinger, B., Erhard, P., Altenmüller, E., Schroeder, U., Boecker, H., \& Ceballos-Baumann, A. O. (2005). Transmodal sensorimotor networks during action observation in professional pianists. J. Cogn. Neurosci.

\section{7, 282-293. https://doi.org/10.1162/0898929053124893}

Jensenius, A. R., Wanderley, M. M., Godøy, R. I., \& Leman, M. (2010). Musical gestures: Concepts and methods in research. In R. I. Godøy \& M. Leman (Eds.), Musical gestures: Sound, movement, and meaning. New York: Routledge, 12-35.

Lakoff, G. and Johnson, M. (2003). Metaphors We Live By. Chicago: Chicago UP. (Original work published 1980). https://doi.org/10.7208/chicago/9780226470993.001.00 $\underline{01}$

Leman, M. and Godøy, R. (2010). Why study musical gestures? In R. Godøy and M. Leman (Eds.), Musical Gestures: Sound, Movement, and Meaning. New York: Routledge, 3-11.

Maes, P., Leman, M., Palmer, C., \& Wanderley, M. (2014). Action-based effects on music perception. Front. Psych. 4: 1008. https://doi.org/10.3389/fpsyg.2013.01008 